\title{
An integrated model of science communication - More than providing evidence
}

\section{Nancy Longnecker}

\section{Abstract}

Keywords

Context
Factors that influence reception and use of information are represented in this koru model of science communication using the metaphor of a growing plant. Identity is central to this model, determining whether an individual attends to information, how it is used and whether access to it results in increased awareness, knowledge or understanding, changed attitudes or behaviour. In this koru model, facts are represented as nutrients in the soil; the matrix influences their availability. Communication involves reorganisation of facts into information, available via channels represented as roots. When information is taken up, engagement with it is influenced by external factors (social norms, support and control) and internal factors (values, beliefs, attitudes, awareness, affect, understanding, skills and behaviour) which affect whether the individual uses it to form new knowledge.

Public engagement with science and technology; Science communication: theory and models

Science communication is like gardening. Many can do it, but to become adept one needs to be interested, be willing to learn from others and gain experience, to have a plan, be prepared to experiment, occasionally fail and learn from failure and to reflect on outcomes. It is useful to recognise that there are differences between a novice's enthusiastic attempts and those of a professional. That is not to say that novices cannot produce good outcomes. But all science communicators can benefit from an understanding of key principles and reflection about the craft. And all science communicators can improve with increased understanding of how people receive and use information.

This essay presents an integrated model of science communication, drawing from a wide range of disciplines and literature. The model builds on previous models of science communication which focus on the flow of information. This model adds factors that influence an individual's response to information and its use.

Many scientists are keen to share results of their work with the wider community [Besley, Oh and Nisbet, 2013; Besley et al., 2016; Grand et al., 2015; Jensen and Holliman, 2016]. It can surprise some when presentation of well conducted research goes unnoticed or does not result in hoped for changes in attitudes or 
behaviour. There is good reason for audiences to be sceptical. Healthy scepticism is an important aspect of critical thinking [Ennis, 1962]. Additionally, trust in research conducted in publically funded organisations has been weakened by breaches of an unspoken contract. Whilst rare, breaches can be serious and damaging, having included cover-ups [Smith, Young and Gibson, 1999], fraudulence [Larson et al., 2011] and potential conflicts of interest arising from pressure on research organisations and researchers to secure funding [Gulbrandsen and Smeby, 2005]. Both trust [Frewer, Scholderer and Bredahl, 2003; Wynne, 1992; Wynne, 2006] and credibility of the source of information [Wynne, 1992] are factors that impact effectiveness of science communication.

Lack of personal control by users of research results can fuel distrust on issues such as medical treatment [Larson et al., 2011; Lee and Garvin, 2003], use of personal tissues [Skloot, 2011] and development and adoption of new technologies, [Brossard et al., 2009; Frewer, Scholderer and Bredahl, 2003]. The response of many science communicators to distrust or scepticism is to counter with more evidence to support their argument. While evidence is invaluable in critical thinking and deliberate decision making [Ahteensuu, 2011; Petty, McMichael and Brannon, 1992] many decisions are made quickly and subjectively or intuitively [see Kahneman, 2011, for overview]. Evidence alone is insufficient to convince people to change beliefs or practices.

Existing models of science communication include the Deficit Model and Dialogic Model [Ahteensuu, 2011; Brossard and Lewenstein, 2010; Bucchi, 2008; Nisbet and Scheufele, 2009] and models of Participatory or Citizen Science in which communication is vital [Bonney et al., 2014]. These describe communication from the perspective of science, scientists and organsiations. Many science communicators focus on making their information clear and accessible which is indeed a vital part of science communication [Longnecker and Gondwe, 2014]. However for effective science communication, normative factors [Cialdini, 2003] and emotional state [Fredrickson and Branigan, 2005] can play important and interdependent roles alongside clarity of information. This model of science communication includes transmission of information and adds greater focus to factors that affect individual use of that information to develop knowledge and potentially acquire wisdom.

Koru model of
science
communication -
an overview

The metaphor used in this model of science communication (see figure 1) depicts the individual as a growing plant, with facts as nutrients in the external matrix. The koru or young fern leaf represents the individual, chosen because of its symbolism of new life and growth in New Zealand Māori culture. The koru provides a reminder that there is value in different ways of seeing and explaining the world [Gondwe and Longnecker, 2015; Gondwe and Longnecker, 2014]. The components of this model are simplified depictions, comprising whole fields of professional activity, study and research.

There are three main components in this model: communication of information, engagement with that information and use of it. Communication includes transformation of facts into information and is represented in this model as uptake and transport via a variety of channels. Engagement and processing of information can be thought of as metabolism and physiology; use of information in formation 
of attitudes, decision-making and and behavior is represented as growth and development.

Communication is the process through which information is collated from facts in the matrix (soil in this depiction) and transmitted to the organism (a fern) or vice versa. Availability of information can be affected by a number of things, including culture (manipulation of the matrix) and the organism itself. Some channels of communication (roots) will be more or less effective for transmission of information for any given individual. An individual's identity is a key aspect that determines their engagement with information and its use. The processing and retention of information and potential conversion into knowledge and decision-making is affected by a variety of influences. In order for individuals to use information, they must have control or access to necessary resources or infrastructure. Support allows individuals to thrive and make most use of what is available. Social norms (the microclimate around individuals) affect how an individual makes meaningful use of information.

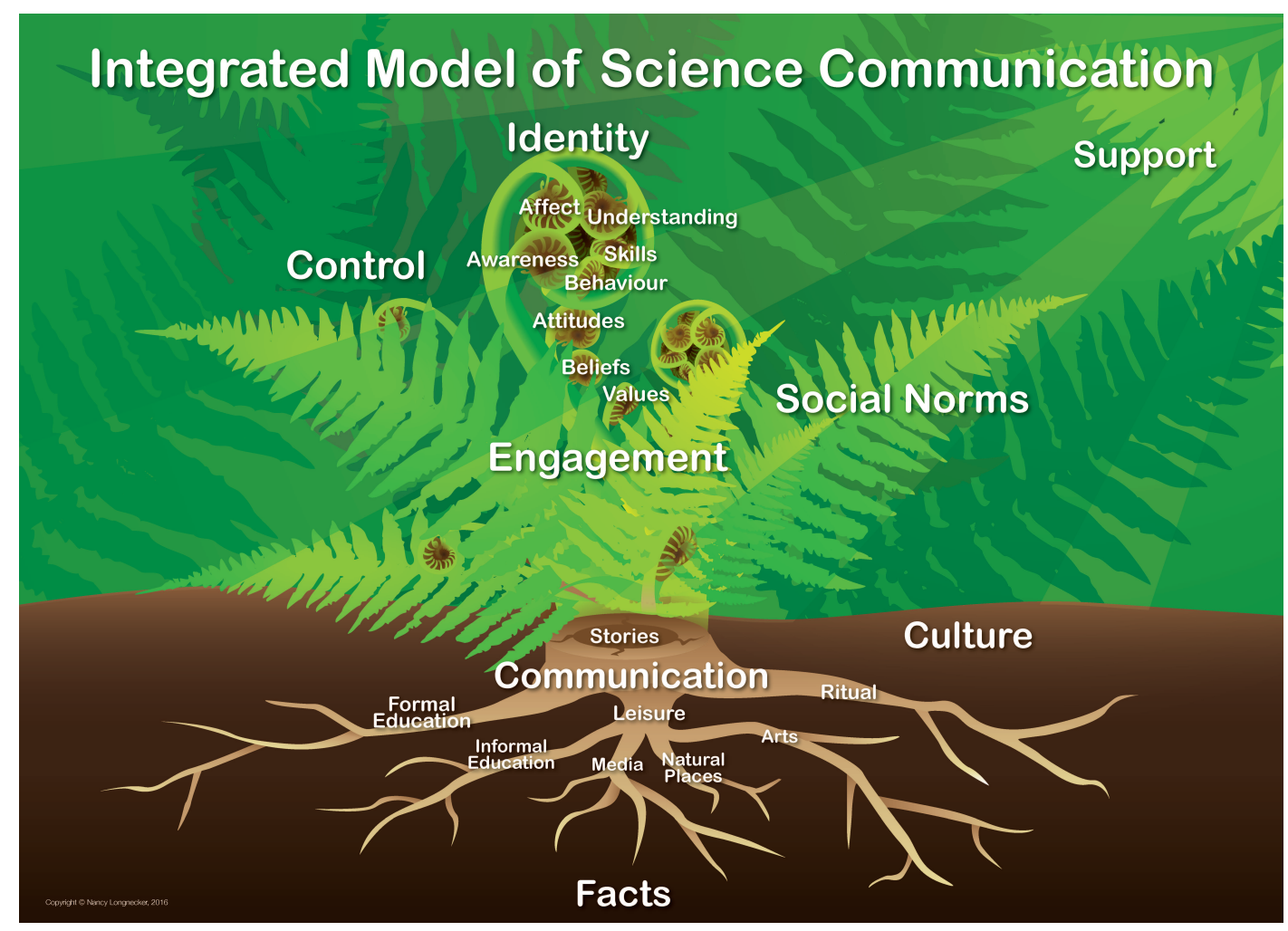

Figure 1. The koru integrated model of science communication. Factors above ground relate to how an individual uses information for growth and development. Below ground relates to collation and synthesis of facts into information that can be communicated via various channels to the individual.

Transforming facts into information
Transforming facts (nutrients in the soil in this model) into coherent information is the first step of effective communication, and is the focus of much of the underground activity depicted in figure 2. Science communicators focus on crafting messages to increase the likelihood that information is noticed, relevant and readily understood, foci that are important for many reasons. Increasing signal to noise ratio can increase attention to a message [Petty, McMichael and Brannon, 1992] and 
framing of messages affects how they are received [Cacciatore, Scheufele and Iyengar, 2016; Roh et al., 2015; Tversky and Kahneman, 1981]. Science

communicators must also select and use appropriate channels to make information more likely to be noticed and taken up by the intended audience.

Culture can strengthen conditions that foster availability and use of information. Ideally, cultural infrastructure that provides channels (including media, libraries, museums, schools and other social structures) ensures availability and effective delivery of information. Through increased relative value of science in society, in particular in traditional media, greater attention may be paid to information about science. Infrastructure that supports research and communication of its results provides new facts and information.

An issue with this focus on messages and channels of communication is that it appears uncomfortably similar to a Deficit Model of science communication [Bucchi, 2008] which has been justifiably criticised [Ahteensuu, 2011; Wynne, 2006; Wynne, 1992; Cortassa, 2016]. In the Deficit Model, science communication can be seen as a transfer of information from a high concentration of information (an expert) to a zone of low concentration (a novice) but this does not necessarily take into account the way we learn [Allen et al., 2008; Liu and Falk, 2014] or other valuable sources of knowledge [Ahteensuu, 2011; Gondwe and Longnecker, 2014; Wynne, 1992]. There is a danger of ineffective communication when exclusive focus on availability of information ignores the significant role of the environment and the individual as critical determinants of that information's use. And so this model of science communication has been expanded to include these additional factors.

External factors: social norms, support and control
Once information is made available to the individual (the fern in this model), that information must be received and processed in order for it to result in change. Whether information is used by any individual is complex and influenced by a variety of factors - what is happening around the individual, how well that information fits into an existing framework of knowledge and views, the life stage of the individual and their particular needs. Social perceptions and norms impact attention to information [Kahan et al., 2012; Cialdini, 2003; Cacciatore, Scheufele and Iyengar, 2016]. The Theory of Planned Behavior [Ajzen, 1991] notes that individual decision-making and behavior is influenced by what others actually think as well as the individual's perceptions of what others think. The importance of those others to the individual affects whether their opinion matters [Wynne, 1992]. For example, early adopters of a new innovation will have a stronger impact on the rate of adoption of others if those early adopters are respected opinion leaders [Rogers, 2003]. Social influence contributes to an individual's social identity, bolstering a sense of belonging to a particular community. It is important for normative messaging to be congruous with an individual's sense of social identity [Kahan et al., 2012; Cook and Lewandowsky, 2016; Roh et al., 2015; see Harré, 2011, for overview].

In addition to information availability, community approval and external support, the individual must have access to the means of implementing any change. Infrastructure and resources must be available and the individual must have control to enable enactment [Lee and Garvin, 2003; Harré, 2011; Fishbein and Cappella, 2006]. Ideally, policies are put into place that empower individuals to 


\section{Integrated Model of Science Communication}

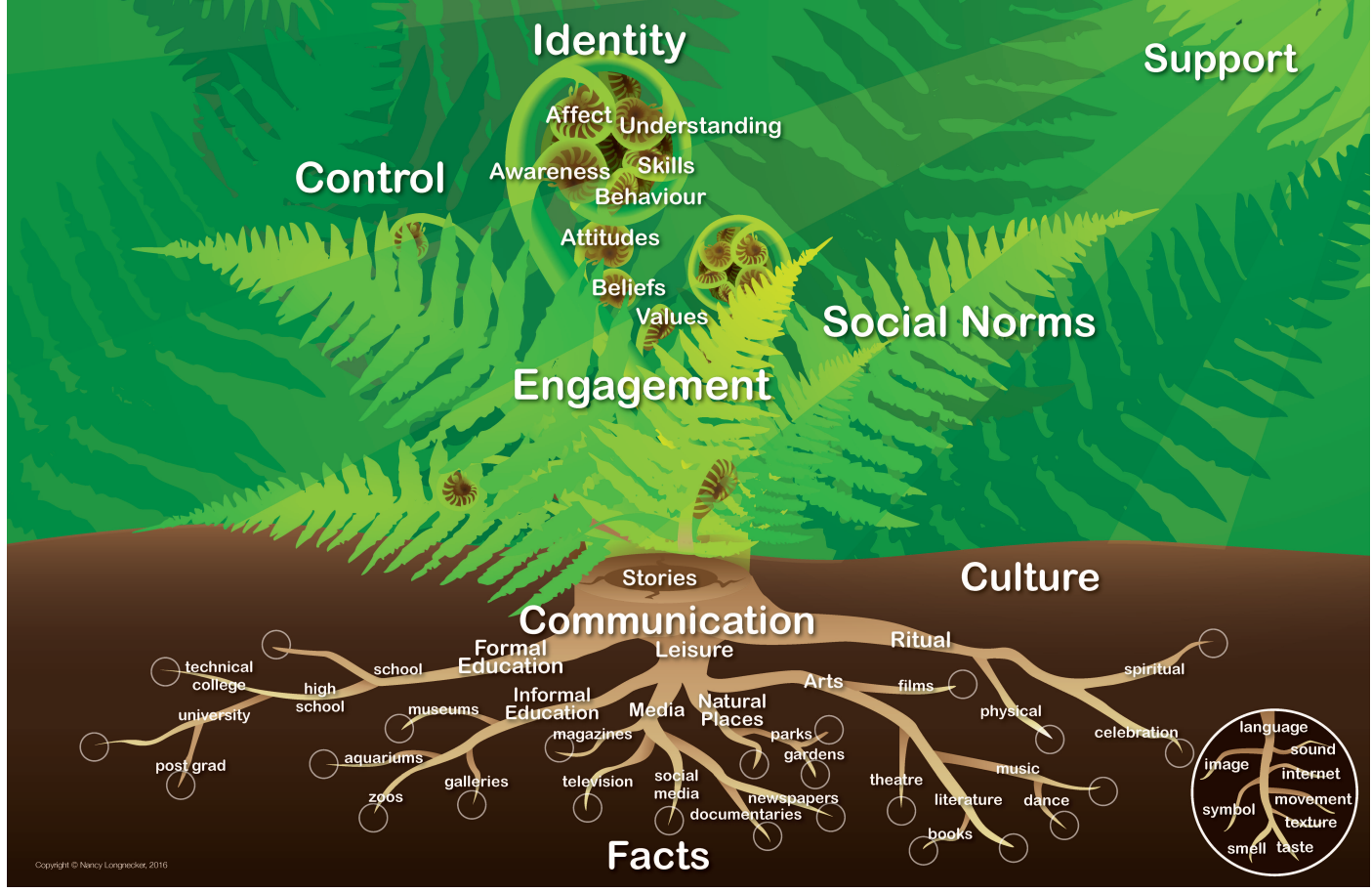

Figure 2. Detailed koru integrated model of science communication. Channels of communication are represented by roots, with different channels likely to be more appropriate and effective for different individuals. Inset: magnification of elements that can increase impact via many channels of communication.

implement their decisions [Abecasis et al., 2013b; Garvin and Eyles, 2001]. The individual must also recognise their ability to implement change [Bandura, 1977; Ryan and Deci, 2000].

Response of the individual: identity and engagement
The koru model presented here considers the construct of identity as central to effectiveness of communication and accommodates the impact of place in shaping identity [Proshansky, Fabian and Kaminoff, 1983]. A sense of identity affects engagement with information - whether we receive it, how we process it and what use we make of it. While consideration of factors that influence information reception and meaning-making are vital to maximise the chance of use of evidence, to focus on availability and clarity of information without consideration of recipients' sense of identity risks ineffective communication [Abecasis et al., 2013a; Hart and Nisbet, 2012; Kahan et al., 2012; Lee and Garvin, 2003]. People have multiple identities (e.g. citizen, parent, scientist, teacher). Motivations to pay attention to and use new information will depend on an individual's focus at any given point in time [see overview by Falk, 2009].

Attention to information or messages can be affected by the source [Rogers, 2003; Wynne, 1992; Wynne, 2006] or even presentation tone [Anderson et al., 2014] but primarily depends on relevance to immediate needs [as reviewed by Falk and Dierking, 2012]. Demographic and socioeconomic factors are often used as objective identity variables that influence information reception and use. Yet 
demographic variables such as socioeconomic status, education, gender and race can be poor predictors of attitudes or response to information [Castelfranchi et al., 2013; and review by Falk, 2009].

In communicating new information, it is important to acknowledge that an individual's acceptance or rejection of information depends to a large extent on that individual's existing cognition, values, beliefs and attitudes [Lee and Garvin, 2003; Harré, 2011]. Internal factors, explored more fully in education and psychology, are used extensively by communicators in fields such as marketing, health promotion, tourism and international development. Personal experiences and reflection on them can sway whether communication is effective in changing or consolidating values, attitudes and behavior [Packer and Ballantyne, 2013; Walker and Moscardo, 2014].

While relevance and levels of awareness, understanding and skill strongly influence an individual's use of communicated information, affect and emotional engagement are also important [Carver, 2001]. For example, recent reception of traumatic news may be detrimental to processing large amounts of new information [Kerr et al., 2003]. Immediately after hearing the diagnosis of a serious disease is unlikley to be the most effective time for a patient to learn about all of their treatment options. Conversely, positive emotional states, may facilitate receptivity to learning [Fredrickson and Branigan, 2005]. Active involvement [Pegrum, Bartle and Longnecker, 2015] and enjoyment [Ainley and Ainley, 2011] are elements that increase propensity for learning [Liu and Falk, 2014]. Fun (which is not necessarily the same as simply being distracted or entertained) can be positively associated with satisfaction [Csikszentmihalyi, 2008] and learning [Liu and Falk, 2014; Packer and Ballantyne, 2004].

Providing evidence is insufficient to convince people to take notice or to change values, attitudes or behavior. As described by the constructivist model of learning, people make sense of the world in ways that fit with what they already know. With the vast availability of information online, people can access and focus on information that reinforces pre-existing views [Vaccari, 2013]. Once a narrative is accepted and incorporated into personal understanding, it is hard to change [Cook and Lewandowsky, 2016; Larson et al., 2011], especially if that understanding is shared by the person's social network [Harré, 2011]. When new information does not fit with existing knowledge, cognitive dissonance can occur; potential responses include ignoring the new information, restructuring the framework to accommodate it or holding onto faulty knowledge in preference to no explanation whatsoever [Lewandowsky et al., 2012]. Effective science communication which takes into account internal and external factors that affect response as well as production of accurate and clear information is an important means of providing well grounded and trustworthy information.

Practical implications
Humans are by nature curious, playful and explorative [Csikszentmihalyi, 2008; Liu and Falk, 2014; Venville et al., 2013] and interest in science is often high [Gaskell et al., 2011]. There is value in scientists communicating about their work with people outside of their own discipline and many recognise this and strive to communicate more effectively [Besley, Oh and Nisbet, 2013; Besley et al., 2016; Grand et al., 2015; Jensen and Holliman, 2016]. There is no single recipe for 
successful communication. The aim of good science communication is to provide something satisfying and potentially useful. This koru model provides a framework to consider the many variables that produce unique communication outcomes. It illustrates why it is difficult to predict when any given communication effort might produce an ordinary result or when it might produce something exceptional.

The koru model of science communication serves as a reminder that while evidence is vital for communication, it is not enough. Other conditions must be met for facts to be synthesised into information and for that information to be used. Many science metaphors come to mind when considering the point that providing information or evidence is not enough to ensure effective science communication. All constituents may be present but a catalyst may be required before information can be used. Nucleation may be necessary for the information to take shape. Other conditions (social norms, support, culture, control) can affect the rate of reaction.

A useful metaphor that is pertinent to this koru model is Liebig's Law of the Minimum (Figure 3) which states that plant growth is restricted by the most limiting factor. Communication efforts may be ineffective if they focus solely on providing information that is clearer, more accurate, or simply more abundant (more water in the barrel) when something else is limiting the use of that information.

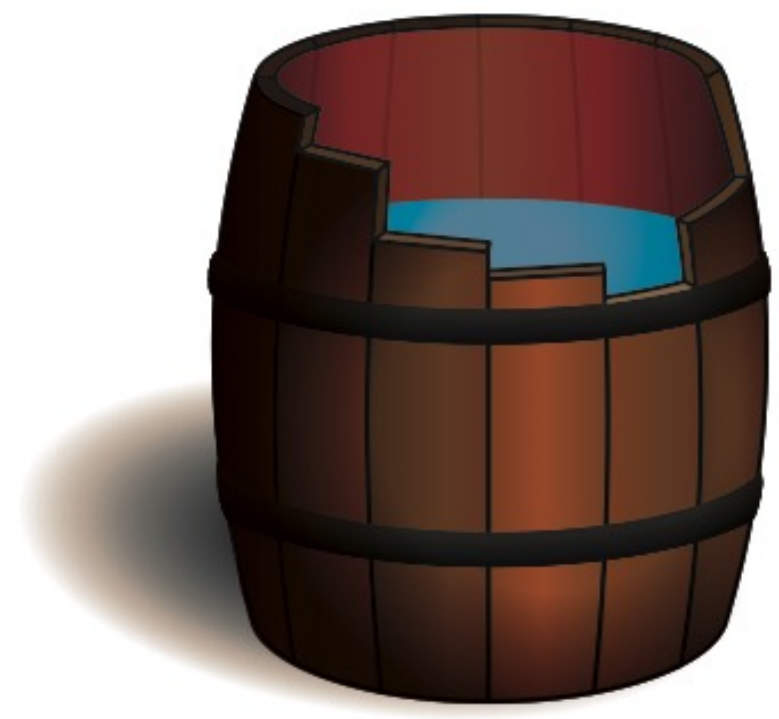

Figure 3. Liebig's Law of the Minimum states that growth is determined by the most limiting factor. Its relevance to this koru model is that adding more information will not result in increased understanding or change if there is another limiting factor.

In order to maximise chances of science communication being effective, it is important to accommodate how facts are transformed into information and to recognise both internal and external factors that affect how that information is perceived, processed and integrated into a personal framework and used.

It is disingenuous to claim that the role of science communication is simply to provide evidence so that people can make evidence-based decisions. Science 
communication, which can include health promotion, agricultural extension and environmental education, often aims to persuade. Some think it is unnecessary or even inappropriate to involve emotions and values in communicating persuasive messages, especially when those messages are straightforward. But there are many examples of unambiguous and well supported, yet ineffective messages: 'Stop smoking because it is bad for you and those around you'; 'We must develop alternative sources of energy and adopt more sustainable lifestyles'. How individuals receive and process information into knowledge and use new knowledge to make decisions is not a straightforward process. And decisions made in response to information may appear illogical to someone who views the same information from a different perspective. This koru model presents a visual and conceptual checklist of factors to consider before development or delivery of a communication effort. The aim is more efficient and targeted use of time and other resources with greater likelihood of effectiveness of science communication.

Acknowledgments I thank Dan Hutton for production of the figures and numerous colleagues and students for useful feedback, especially Massimiano Bucchi, Jean Fletcher, Guy Frederick, Andrea Liberatore, Janis Russell, Miriam Sullivan and anonymous reviewers for suggestions on the manuscript. Any problems with this model remain my responsibility.

Conflict of interest statement

\section{References}

Work for this paper was conducted in the absence of any commercial or financial relationships that could be construed as a potential conflict of interest.
Abecasis, R. C., Schmidt, L., Longnecker, N. and Clifton, J. (2013a). 'Implications of community and stakeholder perceptions of the marine environment and its conservation for MPA management in a small Azorean island'. Ocean $\mathcal{E}$ Coastal Management 84, pp. 208-219. DOI: 10.1016/j.ocecoaman.2013.08.009.

Abecasis, R. C., Longnecker, N., Schmidt, L. and Clifton, J. (2013b). ‘Marine conservation in remote small island settings: Factors influencing marine protected area establishment in the Azores'. Marine Policy 40, pp. 1-9. DOI: 10.1016/j.marpol.2012.12.032.

Ahteensuu, M. (2011). 'Assumptions of the Deficit Model Type of Thinking: Ignorance, Attitudes, and Science Communication in the Debate on Genetic Engineering in Agriculture'. Journal of Agricultural and Environmental Ethics 25 (3), pp. 295-313. DOI: 10.1007/s10806-011-9311-9.

Ainley, M. and Ainley, J. (2011). 'Student engagement with science in early adolescence: The contribution of enjoyment to students' continuing interest in learning about science'. Contemporary Educational Psychology 36 (1), pp. 4-12. DOI: $10.1016 / \mathrm{j}$. cedpsych . 2010.08.001.

Ajzen, I. (1991). 'The theory of planned behavior'. Organizational Behavior and Human Decision Processes 50 (2), pp. 179-211. DOI: 10.1016/0749-5978(91) 90020-T. 
Allen, S., Campbell, P. B., Dierking, L. D., Flagg, B. N., Friedman, A. J., Garibay, C., Korn, R., Silverstein, G. and Ucko, D. A. (2008). Framework for Evaluating Impacts of Informal Science Education Projects. Report from a National Science Foundation Workshop. The National Science Foundation, Division of Research on Learning in Formal and Informal Settings.

Anderson, A. A., Brossard, D., Scheufele, D. A., Xenos, M. A. and Ladwig, P. (2014). "The "Nasty Effect": Online Incivility and Risk Perceptions of Emerging Technologies'. Journal of Computer-Mediated Communication 19 (3), pp. 373-387. DOI: $10.1111 /$ jcc4.12009.

Bandura, A. (1977). 'Self-efficacy: toward a unifying theory of behavioral change'. Psychological Review 84 (2), pp. 191-215. PMID: 847061.

Besley, J. C., Oh, S. H. and Nisbet, M. (2013). 'Predicting scientists' participation in public life'. Public Understanding of Science 22 (8), pp. 971-987. DOI: 10.1177/0963662512459315. PMID: 23825262.

Besley, J. C., Dudo, A. D., Yuan, S. and Ghannam, N. A. (2016). 'Qualitative Interviews With Science Communication Trainers About Communication Objectives and Goals'. Science Communication 38 (3), pp. 356-381. DOI: 10.1177/1075547016645640.

Bonney, R., Shirk, J. L., Phillips, T. B., Wiggins, A., Ballard, H. L., Miller-Rushing, A. J. and Parrish, J. K. (2014). 'Citizen science. Next steps for citizen science'. Science 343 (6178), pp. 1436-1437. DOI: 10.1126/science. 1251554.

Brossard, D. and Lewenstein, B. V. (2010). 'A Critical Appraisal of Models of Public Understanding of Science: Using Practice to Inform Theory'. In: Communicating Science; New Agendas in Communication. Ed. by L. Kahlor and P. A. Stout. New York, U.S.A.: Routledge, Taylor \& Francis, pp. 11-39.

Brossard, D., Scheufele, D. A., Kim, E. and Lewenstein, B. V. (2009). 'Religiosity as a perceptual filter: examining processes of opinion formation about nanotechnology'. Public Understanding of Science 18 (5), pp. 546-558. DOI: 10.1177/0963662507087304.

Bucchi, M. (2008). 'Of deficits, deviations and dialogues: theories of public communication of science'. In: Handbook of Public Communication of Science and Technology. Ed. by M. Bucchi and B. Trench. London, U.K. and New York, U.S.A.: Routledge, pp. 57-76.

Bucchi, M. and Trench, B., eds. (2008). Handbook of Public Communication of Science and Technology. London, U.K. and New York, U.S.A.: Routledge.

Cacciatore, M. A., Scheufele, D. A. and Iyengar, S. (2016). 'The End of Framing as we Know it ... and the Future of Media Effects'. Mass Communication and Society 19 (1), pp. 7-23. DOI: 10.1080/15205436.2015.1068811.

Carver, C. S. (2001). 'Affect and the Functional Bases of Behavior: On the Dimensional Structure of Affective Experience'. Personality and Social Psychology Review 5 (4), pp. 345-356. DOI: 10.1207/S15327957PSPR0504_4.

Castelfranchi, Y., Vilela, E. M., de Lima, L. B., de Castro Moreira, I. and Massarani, L. (2013). 'Brazilian opinions about science and technology: the paradox of the relation between information and attitudes'. História, Ciências, Saúde-Manguinhos 20, pp. 1163-1183. DOI: 10.1590/S0104-59702013000400005.

Cialdini, R. B. (2003). 'Crafting Normative Messages to Protect the Environment'. Current Directions in Psychological Science 12 (4), pp. 105-109. DOI: 10.1111/1467-8721.01242. 
Cook, J. and Lewandowsky, S. (2016). 'Rational Irrationality: Modeling Climate Change Belief Polarization Using Bayesian Networks'. Topics in Cognitive Science 8 (1), pp. 160-179. DOI: 10.1111/tops .12186. PMID: 26749179.

Cortassa, C. (2016). 'In science communication, why does the idea of a public deficit always return? The eternal recurrence of the public deficit'. Public Understanding of Science 25 (4), pp. 447-459. DOI: 10.1177/0963662516629745. PMID: 27117772.

Csikszentmihalyi, M. (2008). Flow: The Psychology of Optimal Experience. New York, NY, U.S.A.: Harper Perennial Modern Classics.

Ennis, R. H. (1962). 'A Concept of Critical Thinking'. Harvard Educational Review 32 (1), pp. 81-111.

Falk, J. H. (2009). Identity and the Museum Visitor Experience. Walnut Creek, CA, U.S.A.: Left Coast Press.

Falk, J. H. and Dierking, L. D. (2012). The Museum Experience Revisited. Walnut Creek, CA, U.S.A.: Left Coast Press.

Fishbein, M. and Cappella, J. N. (2006). 'The Role of Theory in Developing Effective Health Communications'. Journal of Communication 56, S1-S17. DOI: $10.1111 / \mathrm{j} .1460-2466.2006 .00280 . \mathrm{x}$.

Fredrickson, B. L. and Branigan, C. (2005). 'Positive emotions broaden the scope of attention and thought-action repertoires'. Cognition $\mathcal{E}$ Emotion 19 (3), pp. 313-332. DOI: 10.1080/02699930441000238. PMID: 21852891.

Frewer, L. J., Scholderer, J. and Bredahl, L. (2003). 'Communicating about the risks and benefits of genetically modified foods: the mediating role of trust'. Risk Analysis: An Official Publication of the Society for Risk Analysis 23 (6), pp. 1117-1133. PMID: 14641888.

Garvin, T. and Eyles, J. (2001). 'Public health responses for skin cancer prevention: the policy framing of Sun Safety in Australia, Canada and England'. Social Science \& Medicine (1982) 53 (9), pp. 1175-1189. PMID: 11556608.

Gaskell, G., Allansdottir, A., Allum, N., Castro, P., Esmer, Y., Fischler, C., Jackson, J., Kronberger, N., Hampel, J., Mejlgaard, N., Quintanilha, A., Rammer, A., Revuelta, G., Stares, S., Torgersen, H. and Wager, W. (2011). 'The 2010 Eurobarometer on the life sciences'. Nature Biotechnology 29 (2), pp. 113-114. DOI: $10.1038 / \mathrm{nbt} .1771$.

Gondwe, M. and Longnecker, N. (2014). 'Scientific and Cultural Knowledge in Intercultural Science Education: Student Perceptions of Common Ground'. Research in Science Education 45 (1), pp. 117-147. DOI: 10.1007/s11165-014-9416-z.

- (2015). 'Objects as Stimuli for Exploring Young People's Views about Cultural and Scientific Knowledge'. Science, Technology \& Human Values 40 (5), pp. 766-792. DOI: 10.1177/0162243915577452.

Grand, A., Davies, G., Holliman, R. and Adams, A. (2015). 'Mapping public engagement with research in a UK University'. PloS One 10 (4), e0121874, pp. 1-19. DOI: 10.1371/journal. pone.0121874.

Gulbrandsen, M. and Smeby, J.-C. (2005). 'Industry funding and university professors' research performance'. Research Policy 34 (6), pp. 932-950. DOI: 10.1016/j.respol.2005.05.004.

Harré, N. (2011). Psychology for a Better World: Strategies to Inspire Sustainability. Auckland, New Zealand: University of Auckland.

Hart, P. S. and Nisbet, E. C. (2012). 'Boomerang Effects in Science Communication: How Motivated Reasoning and Identity Cues Amplify Opinion Polarization About Climate Mitigation Policies'. Communication Research 39, pp. 701-723. 
Jensen, E. and Holliman, R. (2016). 'Norms and Values in UK Science Engagement Practice'. International Journal of Science Education, Part B 6 (1), pp. 68-88. DOI: 10.1080/21548455.2014.995743.

Kahan, D. M., Peters, E., Wittlin, M., Slovic, P., Ouellette, L. L., Braman, D. and Mandel, G. (2012). 'The polarizing impact of science literacy and numeracy on perceived climate change risks'. Nature Climate Change 2, pp. 732-735. DOI: 10.1038/nclimate1547.

Kahneman, D. (2011). Thinking, Fast and Slow. London, U.K.: Allen Lane, the Penguin Group.

Kerr, J., Engel, J., Schlesinger-Raab, A., Sauer, H. and Hölzel, D. (2003).

'Communication, quality of life and age: results of a 5-year prospective study in breast cancer patients'. Annals of Oncology 14 (3), pp. 421-427. PMID: 12598348.

Larson, H. J., Cooper, L. Z., Eskola, J., Katz, S. L. and Ratzan, S. (2011). 'Addressing the vaccine confidence gap'. The Lancet 378 , pp. 526-535. DOI: 10.1016/S0140-6736(11)60678-8.

Lee, R. G. and Garvin, T. (2003). 'Moving from information transfer to information exchange in health and health care'. Social Science $\mathcal{E}$ Medicine 56 (3), pp. 449-464. PMID: 12570966.

Lewandowsky, S., Ecker, U. K. H., Seifert, C. M., Schwarz, N. and Cook, J. (2012). 'Misinformation and Its Correction: Continued Influence and Successful Debiasing'. Psychological Science in the Public Interest 13 (3), pp. 106-131. DOI: 10.1177/1529100612451018. PMID: 26173286.

Liu, C.-C. and Falk, J. H. (2014). 'Serious Fun: Viewing Hobbyist Activities through a Learning Lens'. International Journal of Science Education, Part B 4 (4), pp. 343-355. DOI: 10.1080/21548455.2013.824130.

Longnecker, N. and Gondwe, M. (2014). 'Graduate Degree Programmes in Science Communication: Educating and Training Science Communicators to Work with Communities'. In: Communicating Science to the Public: Opportunities and Challenges for the Asia-Pacific Region. Ed. by L. T. W. Hin and R. Subramaniam, pp. 141-160. DOI: 10.1007/978-94-017-9097-0_9.

Nisbet, M. C. and Scheufele, D. A. (2009). 'What's next for science communication? Promising directions and lingering distractions'. American Journal of Botany 96 (10), pp. 1767-1778. DOI: 10.3732/ajb.0900041.

Packer, J. and Ballantyne, R. (2004). 'Is Educational Leisure a Contradiction in Terms? Exploring the Synergy of Education and Entertainment'. Annals of Leisure Research 7 (1), pp. 54-71. DOI: 10.1080/11745398.2004.10600939.

- (2013). 'Encouraging reflective visitor experiences in ecotourism'. In: International handbook on ecotourism. Ed. by J. Packer and R. Ballantyne. Cheltenham, U.K.: Edward Elgar Publishing, pp. 169-177.

Pegrum, M., Bartle, E. and Longnecker, N. (2015). 'Can creative podcasting promote deep learning? The use of podcasting for learning content in an undergraduate science unit'. British Journal of Educational Technology 46 (1), pp. 142-152. DOI: 10.1111/bjet. 12133.

Petty, R. E., McMichael, S. and Brannon, L. A. (1992). 'The elaboration likelihood model of persuasion: Applications in recreation and tourism'. In: Influencing human behaviour: Theory and applications in recreation, tourism and natural resources management. Ed. by M. Manfredo. Champaign, IL, U.S.A.: Sagamore Publishing, pp. 77-101.

Proshansky, H. M., Fabian, A. K. and Kaminoff, R. (1983). ‘Place-identity: Physical world socialization of the self'. Journal of Environmental Psychology 3 (1), pp. 57-83. DOI: 10 . 1016/S0272-4944 (83) 80021-8. 
Rogers, E. M. (2003). Diffusion of Innovations. 5th ed. New York, NY, U.S.A.: Free Press.

Roh, S., McComas, K. A., Rickard, L. N. and Decker, D. J. (2015). 'How Motivated Reasoning and Temporal Frames May Polarize Opinions About Wildlife Disease Risk'. Science Communication 37 (3), pp. 340-370. DOI: 10.1177/1075547015575181.

Ryan, R. M. and Deci, E. L. (2000). 'Self-determination theory and the facilitation of intrinsic motivation, social development, and well-being'. The American Psychologist 55 (1), pp. 68-78. PMID: 11392867.

Skloot, R. (2011). The Immortal Life of Henrietta Lacks. New York, NY, U.S.A.: Crown.

Smith, A. P., Young, J. A. and Gibson, J. (1999). 'How now, mad-cow? Consumer confidence and source credibility during the 1996 BSE scare'. European Journal of Marketing 33 (11), pp. 1107-1122. DOI: 10.1108/03090569910292294.

Smith, J., Lipsitch, M. and Almond, J. W. (2011). 'Vaccine production, distribution, access, and uptake'. Lancet 378, pp. 428-438. DOI: 10.1016/S0140-6736 (11)60478-9. PMID: 21664680.

Tversky, A. and Kahneman, D. (1981). 'The framing of decisions and the psychology of choice'. Science 211 (4481), pp. 453-458. DOI: 10.1126/science.7455683. PMID: 7455683.

UNESCO (2003). Science for the 21st century: a vision and basis for action. World Conference Declaration on Science and the Use of Scientific Knowledge, scientific agenda, action plan, Budapest and Santo Domingo, 1999. Brasília, Brasil: UNESCO. URL: http://unesdoc. unesco.org/images/0013/001315/131550e.pdf.

Vaccari, C. (2013). 'From echo chamber to persuasive device? Rethinking the role of the Internet in campaigns'. New Media E Society 15 (1), pp. 109-127. DOI: 10.1177/1461444812457336.

Venville, G., Rennie, L., Hanbury, C. and Longnecker, N. (2013). 'Scientists Reflect on Why They Chose to Study Science'. Research in Science Education 43 (6), pp. 2207-2233. DOI: 10.1007/s11165-013-9352-3.

Walker, K. and Moscardo, G. (2014). 'Encouraging sustainability beyond the tourist experience: ecotourism, interpretation and values'. Journal of Sustainable Tourism 22 (8), pp. 1175-1196. DOI: 10.1080/09669582.2014.918134.

Wynne, B. (1992). 'Misunderstood misunderstanding: social identities and public uptake of science'. Public Understanding of Science 1 (3), pp. 281-304. DOI: 10.1088/0963-6625/1/3/004.

- (2006). 'Public Engagement as a Means of Restoring Public Trust in Science Hitting the Notes, but Missing the Music?' Community Genetics 9 (3), pp. 211-220. DOI: 10.1159/000092659. 
Nancy is Professor of Science Communication at the University of Otago in Dunedin, New Zealand. Otago's Centre for Science Communication is one of the world's largest postgraduate facility for study and research of Science

Communication. Before becoming a science communication academic, Nancy was an agricultural research scientists and a professional science communicator with a cooperative research centre in Australia. Her current research looks at factors that affect people's attitudes towards science-related issues and aims to improve impact of science engagement. E-mail: nancy.longnecker@otago.ac.nz.

\section{How to cite}

Longnecker, N. (2016). 'An integrated model of science communication - More than providing evidence'. JCOM 15 (05), Y01. 